
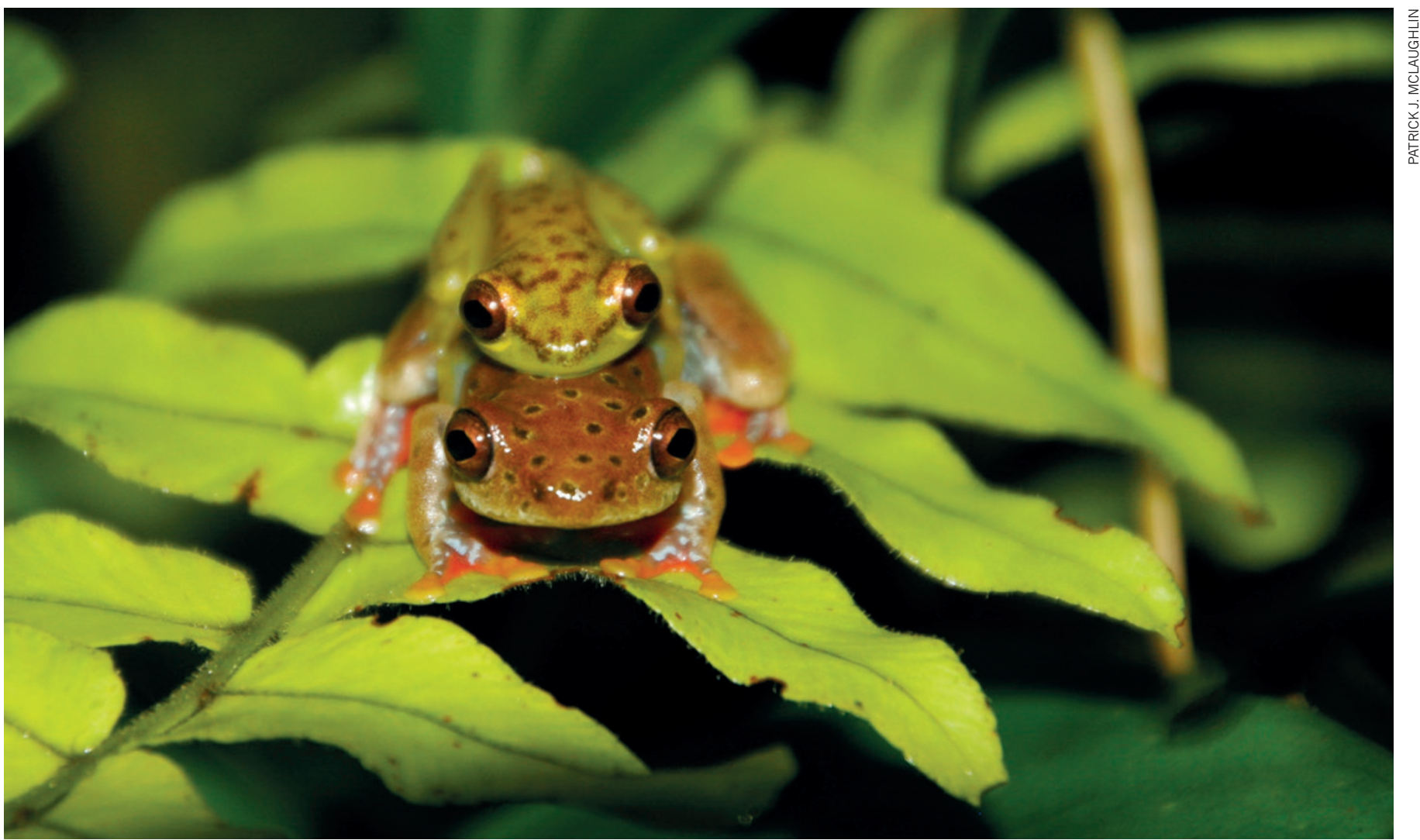

The pattern and colouring of male golden-eyed reed frogs (Hyperolius ocellatus) may help them to entice females.

\title{
Come mate with me
}

\section{In a cut-throat world where only the fittest survive, beauty seems to be a needless expense. But creatures are strutting their stuff in ways that help to perpetuate their species.}

\section{BY AMY MAXMEN}

$\mathrm{O}$ n São Tomé and Príncipe, two tiny islands off the west coast of Africa, Rayna Bell came across Lilliputian frogs, decked out in lime green, speckled in leopard print and daubed with indigos. South and Central America is home to similarly colourful tree frogs, but the goldeneyed reed frogs that Bell saw are not closely related to these - the brilliant patterns had evolved independently multiple times. To Bell, an evolutionary biologist at Cornell University in Ithaca, New York, that fact suggests that such beauty cannot be accidental. "You can't look at these frogs, and not think that something is going on," she says. The question of what that something is drives her research today.

More than 150 years earlier, Charles Darwin had been similarly perplexed by beauty. The trait takes energy to produce and it makes prey easier to spot. A fluorescent orange tree frog

stands no chance of blending into the jungle's backdrop. In a letter to his colleague, the botanist Asa Gray, Darwin wrote, “The sight of a feather in a peacock's tail, whenever I gaze at it, makes me sick!". After years of observations, Darwin proposed an evolutionary concept to account for beauty: sexual selection. Whereas natural selection allows only those who survive to adulthood to pass their genes on to their offspring, sexual selection permits certain individuals to find mates more often than others.

However, strong evidence for Darwin's sexual-selection theory, and an understanding of how it functions, has emerged only in the past decade. This is because many characteristics are nearly impossible for humans to see, and are discovered only by dissecting the sensory systems of the potential mates of

\section{$\rightarrow$ NATURE.COM}

Read more about sexual selection at:

go.nature.com/mmychr every stylish species. A butterfly, after all, is not trying to attract us. Molecular biologists have demonstrated how such visual preferences can lead to entirely new species, and how beauty is meaningful - not just skin deep.

\section{FLASHING THE OPPOSITE SEX}

In Darwin's 1871 book proposing sexual selection, The Descent of Man, and Selection in Relation to Sex, the words 'beauty' and 'beautiful' appear 280 times. Males, Darwin noticed, tended to be the more flamboyant sex in the animal kingdom, and he supposed females were the pickier. However, he did not have strong evidence to demonstrate that females chose aesthetically pleasing males over duller suitors, and he was not sure what benefits decorated males might confer. Acknowledging that he could not fully justify aesthetics, he flirted with the idea that beauty is a by-product. "Hardly any colour is finer than that of arterial blood; but there is no reason to suppose that the colour of the blood is in itself any advantage; and though it adds to the beauty of the maiden's cheek, no one will pretend that it has 
been acquired for this purpose," he wrote'

But Darwin's gaze was limited. Although he travelled, and consulted with zoologists and botanists around the world, no one really knew how varied the senses of sight, smell, touch, sound and taste were among creatures. For example, photosensitive cells in human retinas, called cones, see daylight wavelengths ranging from violet to red, whereas the eyes of some insects see deep into the ultraviolet. And although insect vision is similar to that of humans, inasmuch as they see the world through a series of snapshots that the brain weaves together, insects have a faster rate of capture. As a result, insects perceive much smaller fluctuations in movement than we do. And it turns out that courting insect males use this ability to their advantage.

Biologists have long supposed that the decorated wings of male butterflies attract mates. Indeed, one experiment conducted in the 1950s showed that female Hypolimnas misippus butterflies preferred males with round, baby blue spots on their hind wings to males with those spots artificially blacked out. Realizing that butterflies rarely sit still, Darrell Kemp, an evolutionary biologist at Macquarie University in Sydney, Australia, wondered whether there was more to the story.

Kemp and his team analysed videos of males and females of a related species, Hypolimnas bolina, kept in large cages. They observed how males fluttered below the females that they courted, so that when light reflected off the spots on the males' wings, it struck female eyes at an angle that made the spots luminesce with ultraviolet light. In addition, the courting males beat their wings at a shallower amplitude and faster than they did while they were foraging. This had the visual effect of transforming the spots into quick bursts of light when viewed from above, flashing about 11 times per second ${ }^{2}$. "If you want to really impress a female - or rather, impress her visual system - the best way is to present a bright colour that flashes on and off," says Kemp.

\section{ALTERED SUNBEAMS}

Fish are similarly susceptible to bedazzlement. A mirror-like layer in their eyes bounces light back through the retina, in such a way that photons have a second chance to be captured by photosensitive cells. As a result, a bright flash (as opposed to, say, a steady beam) draws a fish's attention. This is particularly true when the flash contrasts sharply against a murky underwater background.

Molly Cummings, an evolutionary biologist at the University of Texas at Austin, suspected that northern swordtails, Xiphophorus nigrensis - which bounce light of their shiny silver skin in the same way that glaring polarized sunlight is reflected off a lake - might harness polarized light to attract the opposite sex. To test that idea she and her colleagues filmed the

male swordtails in tanks as they swam beside females. By altering the type of artificial light in the tanks, the team could control the ability of the fish to bounce polarized light off their scales. Without polarization, the males lost the attention of the females ${ }^{3}$.

This was not the first time that Cummings had predicted that male ornamentation is based on beholder perception. Earlier in her career, she dove about nine metres below the surface of the ocean in the Californian kelp forests, where light becomes fluid and

"You can't look at these frogs, and not think that something is going on." patchy. Seeing the variety in lighting across the forest, Cummings suggested that surfperch fish see and display features that are tailored to their specific forest backdrop.

When she examined the eyes of one surfperch species, Hypsurus caryi, that swam through variously lit parts of the forest, she found an abundance of opsin proteins ${ }^{4}$. The spectral bands of light that each opsin absorbed hardly overlapped that of other opsins - a trait that enables the fish to perceive greater variation in colours. Males from this species have colouring that corresponds to this visual bias: they have blue and orange markings that stand out against the greenish hue of the algae-filled water. Meanwhile, the surfperch Embiotoca lateralis, which dwells in the densest and dimmest regions of the kelp forest have different eye anatomies. Their opsin proteins cover overlapping spectral regions. These surfperch easily sense the contrast between light and dark, but they are less sensitive to differences in hue. As a result, the allure of the males of this species depends on illumination. Thousands of years ago, these two surfperch species shared a common ancestor. Cummings speculates that their descent from that ancestor might have begun with adaptations that helped the fish to see in their distinct environments. Over time, females developed preferences for males that exhibit features that they could easily see.

Cichlid fish off the Tanzanian shore of Lake Victoria seem to be evolving in this manner as their populations stop mating with one another in the wild - the first step in speciation. At this point, some populations are separate enough from one another that they can be considered distinct species, even though they will breed if isolated in captivity. The fish even differ in the type of visual proteins that they use to perceive colours. Martine Maan, an evolutionary biologist at the University of Groningen in the Netherlands, and her colleagues have found that cichlids in the shallows, which include a broad range of solar wavelengths, perceive a wide spectrum of colour. In turn, males commonly display blue designs, which Mann suggests might hide them from avian predators, while revealing them to female cichlids swimming nearby. Deeper down, at depths birds cannot see and where red light is predominant, photoreceptors in cichlid eyes are shifted towards the longer wavelengths and the males are redder ${ }^{5}$.

Although the two populations of cichlids are neighbours, they no longer mate in the wild because females prefer males that sport the colours that they see best. They might lose the physical ability to interbreed as the populations diverge further. "I'm trying to figure out if adaptations in the visual system, which are driven by ecological requirements, have consequences in how females perceive male colours," says Mann. "That would provide a fast route to speciation."

\section{SHOWING OFF}

These studies do not explain why female fish are so taken by a wash of blue, or why the female butterfly is so dazzled by bursts of light. Their preferences are determined by what their senses tune into - but what do the traits mean?

Occasionally, decorations link directly to benefits. For example, black swans with curly tail feathers tend to be preferred by the opposite sex, and they often occupy the most territory. And, while peering at a common fruit fly at the University of Tromsø in Norway, entomologist Jostein Kjærandsen, discovered a form of beauty that Darwin never suspected, and that seems to come with a pay-off. He noticed that the Drosophila melanogaster's wings reflected a purplish hue against a black background. The wings of other flies from the same species reflected different colours. Soon after, he and his colleagues demonstrated that female fruit flies 


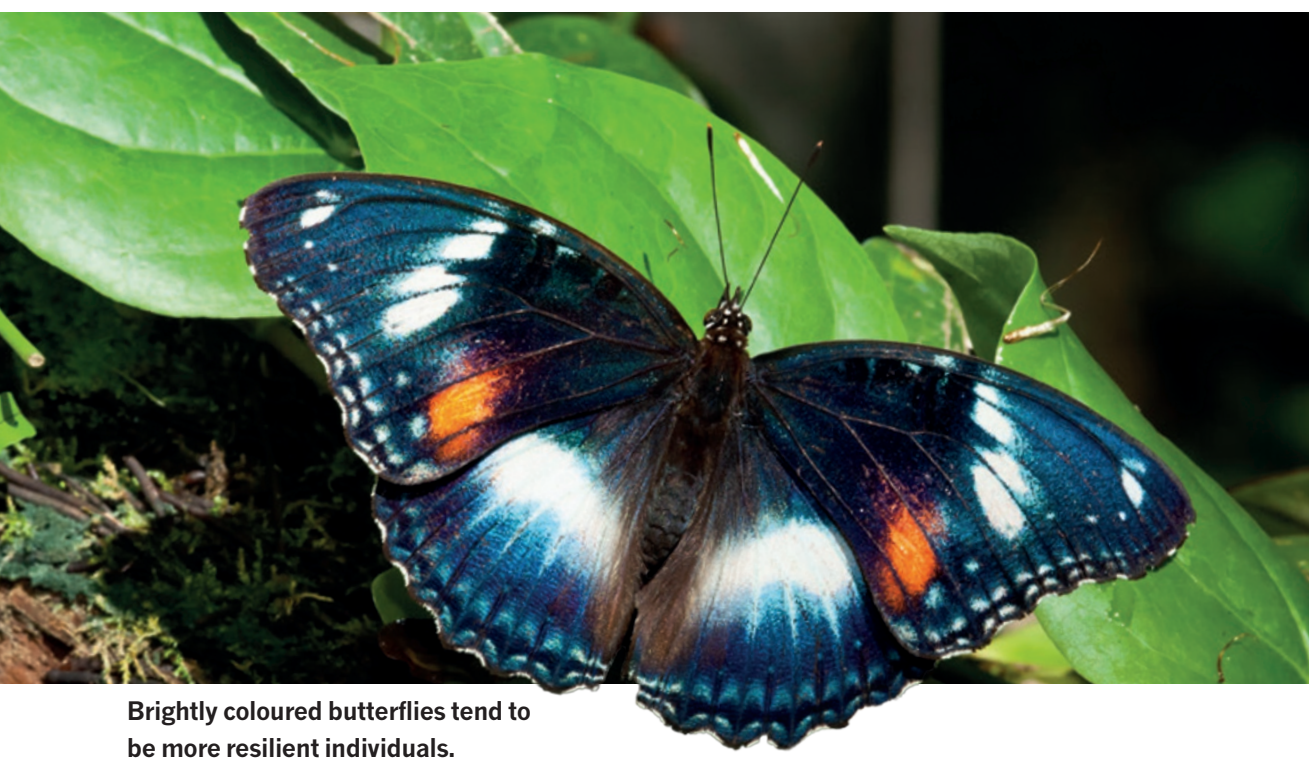

mated more often with males that reflected magenta, as opposed to yellow or blue, sheens ${ }^{6}$. The colours varied depending on the thickness of the wing, the team found, prompting the researchers to speculate that the sheen subtly indicates how well the wings allow flies to control flight. That is a genetically controlled trait that females would find advantageous to endow to their offspring, says Kjærandsen's colleague Erik Svensson at Lund University in Sweden.

D. melanogaster is particularly amenable to advanced genetic manipulation, giving Svensson the opportunity to test the hypothesis. "If we can identify one or several genes that alter characteristics of wings, we could use gene-silencing techniques to manipulate those characteristics and look at the effect on female choice," Svennson says.

Just as frequently, however, beauty links to no obvious benefit. In 1975, biologist Amotz Zahavi proposed the handicap hypothesis to account for extravagant char-

"A woman might find a guy with huge muscles attractive, but I might find him intimidating." acteristics that impair their bearers, but ironically attract mates ${ }^{7}$. Zahavi highlighted the peacock's blue and gold tail that was so loathed by Darwin. It made the birds easy for predators to spot, and gave parasites plenty of feathers to attach to. But the very fact that it persists through the generations means that females like the tails, possibly because the feathers identify males that are healthy enough to withstand the negative effects. Likewise, Kemp suggested that butterflies with the brightest ultraviolet markings make for easier prey than their duller counterparts, but they also withstand turbulence better ${ }^{8}$. Indeed, he found that brilliantly winged male butterflies survived flashes of hot and cold, and malnutrition during juvenile stages more often than did their less-flashy counterparts. Decorations on wings do not themselves confer resilience, but Kemp's study suggests that the trait reveals that vital, but invisible quality. "Females get a genuine glimpse into the potential quality of their mate's genetic quality simply by appraising the quality of his iridescent signal," he says.

\section{SIGNALLING FITNESS}

Earlier this year, researchers found support for the good-genes theory in common yellowthroat warblers, Geothlypis trichas. In New York, female warblers prefer males with large, bright yellow breast feathers. But around 1,500 kilometres west, in Wisconsin, females rate males on the size of their so-called masks - black feathers around their eyes. Despite the different preferences, however, the quality - size and colour - of both yellow bibs and black masks indicates the power of the individual bird's immune system. Greater variation in the genes that are essential in immune responses, called the major histocompatibility complex or MHC genes, correlate with better bibs or masks; this in turn enhances the bird's ability to fend off diverse infections ${ }^{9}$. Females' preference for a bib or a mask is rather arbitrary: it is the signal the features send that counts.

Furthermore, a certain style - a bib, a mask or a haircut, for example - can send different signals, depending on who is looking. "A woman might find a guy with huge muscles attractive, but I might find a guy with huge muscles intimidating," says Ken Kraaijeveld, an evolutionary biologist at VU University Amsterdam. That is efficient from an evolutionary perspective - better to use existing features than develop a feature anew. Kraaijeveld warns that dual-function features can obscure biologists' view. If researchers are most interested in sexual selection, he says, they might focus on how a male bird behaves to attract females in the mating season, and neglect to observe how that same behaviour helps them to find food in the winter.

To complicate matters further, not all males and females want to say 'come mate with me'. Cummings is now comparing male behaviour of various swordtail species. "One type of fish includes the knights of the species, they shimmy to attract females, and if she gives them the right cue, they have cooperative copulation," Cummings says. Not surprisingly, these flirty males are colourful. Meanwhile, males from a closely related species mate by simply thrusting their fish penis, a gonopodium, into an unsuspecting female. Not only are these crude males undecorated, but Cummings has found that females in this species are wired differently than courted females. Specifically, more neural genes associated with learning and memory are activated in courted female fish when they interact with males ${ }^{10}$. That is a tantalizing finding because it suggests that a female's preference may be acquired, and not just genetically determined. In this way, the beholder of beauty can speed up evolution's trajectory.

Although she cannot yet explain it, Rayna Bell is confident the beauty she saw in African reed frogs has meaning - she just needs to discover what the creatures are seeing and silently saying. Few biologists have been to those islands off Africa's west coast. "You don't just swoop in and get the sexy story," Bell says. "That takes time, but I don't mind. Its exciting to start from almost zero, to realize there's so much diversity that we know so little about."

Cummings, for her part, sees meaning in the 'flush of a maiden's cheek' that Darwin found haphazard. It is no accident that cosmetic companies sell pink rouge and red lipstick, rather than blue. "Red mimics a youthful glow," she says. "It advertises that the wearer is young and reproductively valuable." And from a survival of the species perspective, that is truly a beautiful thing.

Amy Maxmen is a freelance science writer in Berkeley, California.

1. Darwin, C. R. The Descent of Man, and Selection in Relation to Sex (John Murray, 1871).

2. White, T. E., Zeil, J. \& Kemp, D. J. Evolution 69, 14-25 (2015).

3. Calabrese, G. M., Brady, P. C., Gruev, V. \& Cummings, M. E. Proc. Natl Acad. Sci. USA 111, 13397-13402 (2014).

4. Cummings, M. E. Evolution 61, 530-545 (2007).

5. Seehausen, O. Nature 455, 620-626 (2008).

6. Katayama, N., Abbott, J. K., Kjærandsen, J., Takahashi, Y. \& Svensson, E. I. Proc. Natl Acad. Sci. USA 111, 15144-15148(2014).

7. Zahavi, A. J. Theor. Biol. 53, 205-214 (1975).

8. Kemp, D. J. \& Rutowski, R. L. Evolution 61, 168-183 (2007).

9. Whittingham, L. A., Freeman-Gallant, C. R., Taff, C. C. \& Dunn, P. O. Mol. Ecol. 24, 1584-1595 (2015)

10.Cummings, M. E. Anim. Behav. 103, 249-258 (2015). 